\title{
Efficacy of Ligamentotaxis of the Intact and Ruptured Posterior Longitudinal Ligament in Dorso-Lumbar Traumatic Spine Injuries
}

\author{
Borkar Santosh S1, Konde Shivraj S2, Kulkarni Priya Y ${ }^{3}$, Borkar Sumita S4 \\ ${ }^{1}$ Associate Professor, ${ }^{2}$ Assistant Professor, Department of Orthopedics, ${ }^{4}$ Senior Resident, Department of Anaesthesia, \\ MIMER Medical College, Talegaon, Pune, Maharashtra, India. \\ ${ }^{3^{*}}$ Associate Professor, Community Medicine, SMBT Medical College, Nasik, Maharashtra, India.
}

\begin{abstract}
Background: The treatment of compression and burst fractures of the thoracolumbar and mid-lumbar spines still remains controversial. Good results are reported by both operative and non-operative treatment.

Aim: To assess efficacy of ligamentotaxis of the intact and ruptured posterior longitudinal ligament in dorso-lumbar traumatic spine injuries.

Material and Methods: It was a prospective study carried out at Grant Medical College and J J Hospital, Byculla, Mumbai during three consecutive calendar years. Patients with traumatic dorso-lumbar fractures were included. Posterior longitudinal ligament status was noted from MRI scans done within $48 \mathrm{hrs}$ after trauma. Patients were managed by operative and non-operative treatment as per indications and affordability. Operative treatment in the form of ligamentotaxis by posterior approach using pedicle screw or Hartshill rectangular and sublaminar wires or Harrington rods with hooks was done. If ligamentotaxis was not successful, direct posterior decompression or transpedicular route decompression with or without bone grafting was done. All the necessary post-operative care, monitoring, evaluation for improvement by neurological charting was done. Patients were mobilized with support after suture removal depending on stability and neurological status.
\end{abstract}

Results: 19 patients with dorso-lumbar fractures were studied. $52.63 \%$ patients had severe cord injuries. PLL was ruptured in $47.37 \%(9 / 19)$ patients and intact in $52.63 \%$ (10/19) patients.

\section{INTRODUCTION}

Tough, spinal fractures are frequently located at the thoracolumbar junction due to biomechanical aspects, dorsolumbar trauma is more severe. It is the most common cause of paraparesis or paraplegia. Fall from height is the most common cause of dorsolumbar fracture. Majority of these cases belong to younger age group. Dorsolumbar fractures often cause a neurologic deficit and present a significant economic burden to the family and society. Accepted methods of treatment of dorsolumbar burst fractures include conservative therapy, posterior reduction and instrumentation, and anterior decompression and instrumentation..$^{1,2}$

Thoraco-lumbar fractures are graded by $\mathrm{AO}$ classification with increasing severity as:

Type A: vertebral compression fractures;

Type B: anterior and posterior column injuries with distraction; Type C: anterior and posterior element injury with rotation. ${ }^{3}$

Type A injuries are the result of compression by axial loading, for example compression and burst fractures. ${ }^{4}$
PLL rupture was significantly more in severe cord injuries (7/10). Ligamentotaxis was done in 7 cases with ruptured PLL and 4 cases with intact PLL. Success rate was $100 \%$ when PLL was intact while ligamentotaxis was $100 \%$ unsuccessful when PLL was ruptured and in these cases either direct posterior decompression or transpedicular route decompression with or without bone grafting was done. But, power did not improve in 4 out of 7 such cases.

Conclusion: Ligamentotaxis worked very well if posterior longitudinal ligament intact.

Key words: Ligamentotaxis, Dorso-lumbar spinal cord injuries, Posterior longitudinal ligament.

\section{${ }^{*}$ Correspondence to:}

Dr Kulkarni Priya $Y$,

5, Shanti Sadan, Tarte Colony,

Erandawane, Pune, Maharashtra, India.

Article History:

Received: 03-06-2016, Revised: 15-06-2016, Accepted: 26-06-2016

\begin{tabular}{|l|c|}
\hline \multicolumn{2}{|c|}{ Access this article online } \\
\hline $\begin{array}{l}\text { Website: } \\
\text { www.ijmrp.com }\end{array}$ & Quick Response code \\
\hline DOI: & \\
10.21276/ijmrp.2016.2.4.023 & \\
\hline
\end{tabular}

Though, standard radiographs and CT scans can serve as imaging modalities, MRI scan is extremely useful to view ligaments (Fig 1) and to know status of spinal cord lesions and disco-ligamentous injuries. ${ }^{5}$

Fractures are considered stable if no injury to ligaments or discs is evident like pure impaction fractures (Type A1). In slightly unstable fractures, there is partial damage of ligaments and intervertebral discs. These fractures heal under functional treatment without gross deformity and without additional neurological deficit.

For unstable fractures and neurological deficits, like in majority of dorso-lumbar spine injuries due to fall, there is a general trend towards operative treatment in the form of early stabilization and fusion. 6,7 Conventional surgical approaches for the treatment thoraco-lumbar fractures require extensive exposure and often lead to significant post-operative pain and morbidity. ${ }^{8}$

For patients with less instability, moderate deformity and absence of neurological compromise, yet the optimal treatment remains a 
matter of debate. Good clinical outcome can be achieved with non-operative as well as operative treatment. ${ }^{4}$ But, in patients with neurological compromise restoration of spine canal anatomy is especially utmost important. ${ }^{9}$

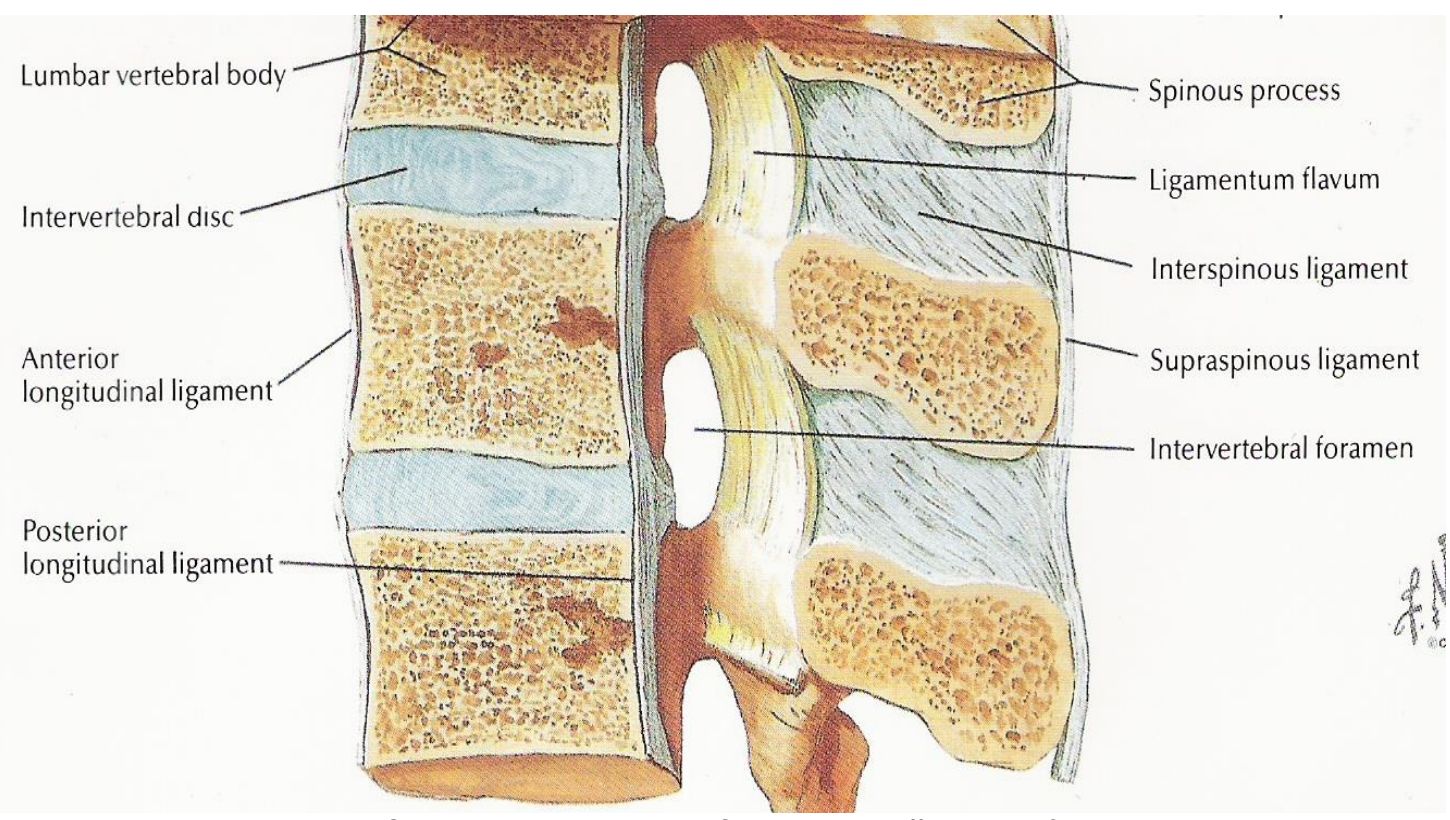

Fig 1: Spine and its ligament; (Source: https://www2.aofoundation.org)

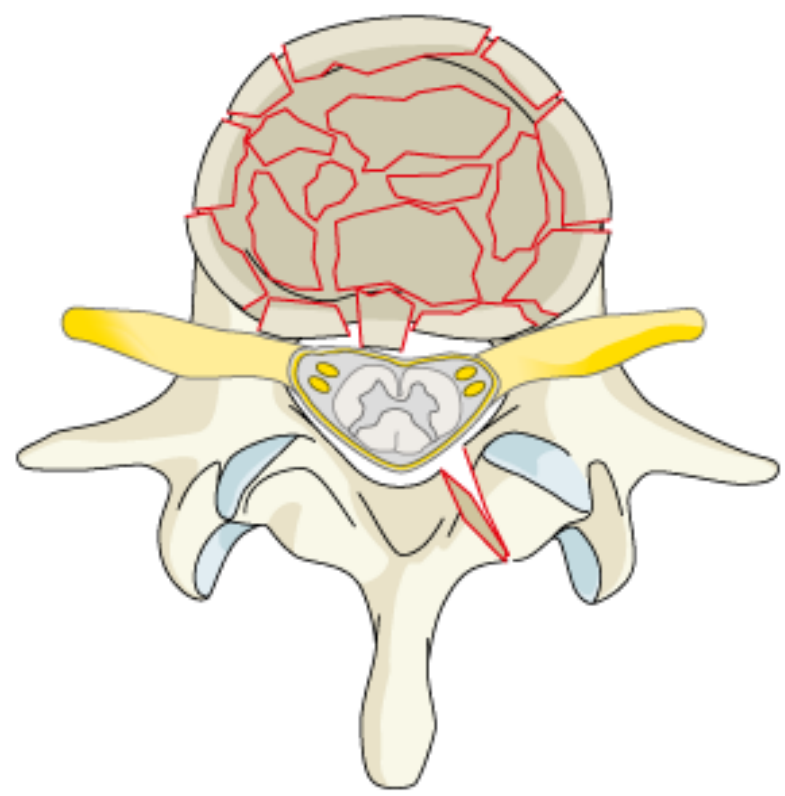

Fig 2: Indications for ligamentotaxis : Type A fractures,

Fresh fractures, Retro-pulsed fragment

Source: https://www2.aofoundation.org

Two opposite techniques are in debate to achieve restoration of the canal size:

1. Anterior direct decompression through a corpectomy followed by anterior vertebral body replacement with cage or graft. And,

2. The posterior approach to the spine and ligamentotaxis using the tension of the posterior longitudinal ligament to push back the retropulsed fragment and restore the size of the canal (Fig 2, Fig 3). ${ }^{10-13}$

Existence of a reverse cortical sign has been classically a contraindication of posterior ligamentotaxis ${ }^{14}$.

Posterior longitudinal ligament (PLL) is often ruptured in unstable bursts fractures, flexion destruction injuries, flexion rotation

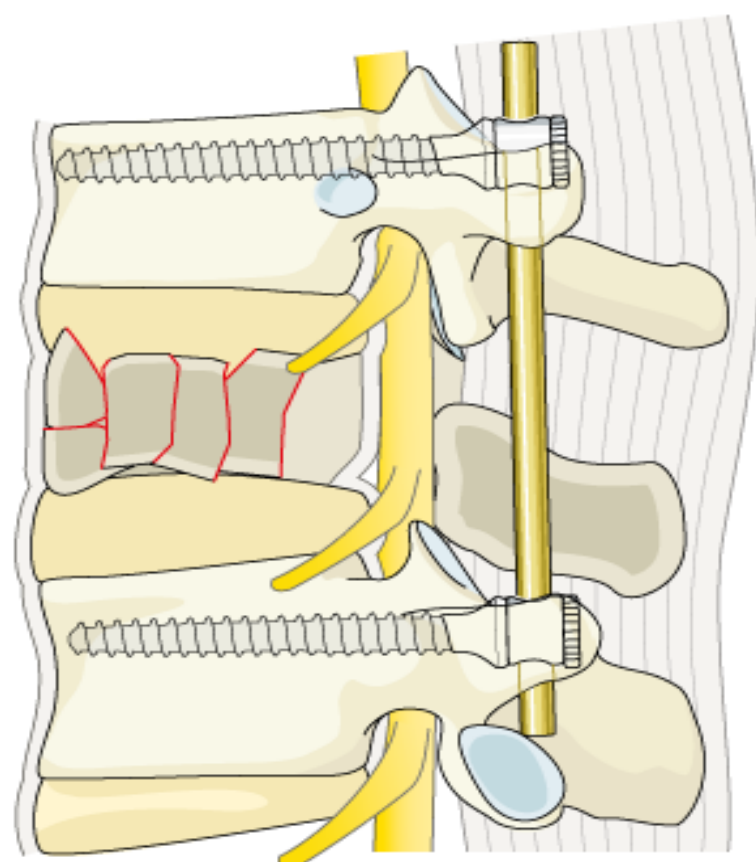

Fig 3: Principle of Ligamentotaxis

Source: https://www2.aofoundation.org

injuries. If PLL is ruptured, spinal cord injury is often severe and prognosis of treatment is doubtful. ${ }^{15}$

In patients with complete or incomplete neurological deficit, in the presence of canal compromise decompression techniques can be used. Ligamentotaxis is indirect reduction technique in which intact but buckled posterior longitudinal ligament (PLL) is used to guide the repositioning of retropulsed fracture fragments by the application of distraction forces. (Fig 2)lt is indicated in only type A fractures, Fresh fractures and Retropulsed fragment. ${ }^{15}$

Purpose of present study was to assess efficiency of ligamentotaxis of the PLL in dorsolumbar spine injuries, according to its status whether intact or ruptured. 


\section{MATERIALS AND METHODS}

It was a prospective study carried out at Grant Medical College and J J Hospital, Byculla, Mumbai. Ethical permission was taken from institutional ethical committee and Head of involved departments. Patients with thoracic thoraco-lumbar and lumbar fractures arrived acutely during three consecutive calendar years were included in the study.

MRI scans were done with 1.5 tesla magnet and $10{ }^{*} 20 \mathrm{~cm}$ rectangular receive only surface coil. ALL and PLL were seen as thin linear signal voids paralleling anterior and posterior borders of the vertebral body and discs. Most patients were imaged within 48 hrs after trauma. PPL status was noted down in each case.

Management consisted of non-operative treatment or conservative treatment for stable injuries (one column injuries). It included bed rest, bowel bladder care, analgesics, water bed and log rolling, braces. Operative treatment in the form of ligamentotaxis was done for some unstable injuries with two or three column injuries which are included in the study. It was preferred for patients with significant neurological deficits, compression fractures with $>50 \%$ vertebral body height, canal compromise $>50 \%$. Posterior approach was the preferred route. Supplemental interconnecting between MIAMI rods significantly increased the pedicle screw construct stiffness without morbidity of fusing additional levels. (Fig $4,5,6)$

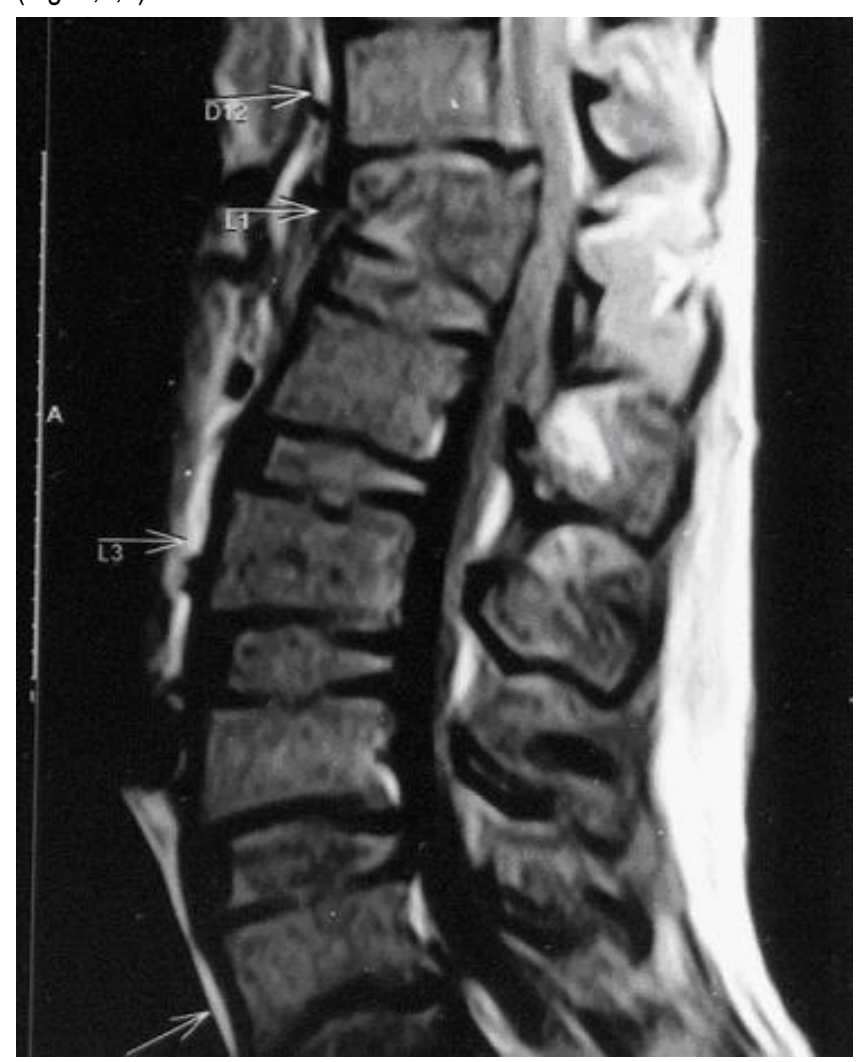

Fig 5: Example of dorsolumbar spine injury from cases under studuy

In non-affording patients, hartshill rectangular and sublaminar wires or Harrington rods with hooks were used instead of pedicle screw or rod construct. Short posterior constructs were used for flexion distraction with intact anterior column, mild bursts fractures or fracture dislocations of minor degree. lliac crest corticocancellous grafts and local bone grafts harvested from lamina, spinous processes and transverse processes were used whenever required. Intraoperative $\mathrm{C}$ arm was used to see implants and level identification.

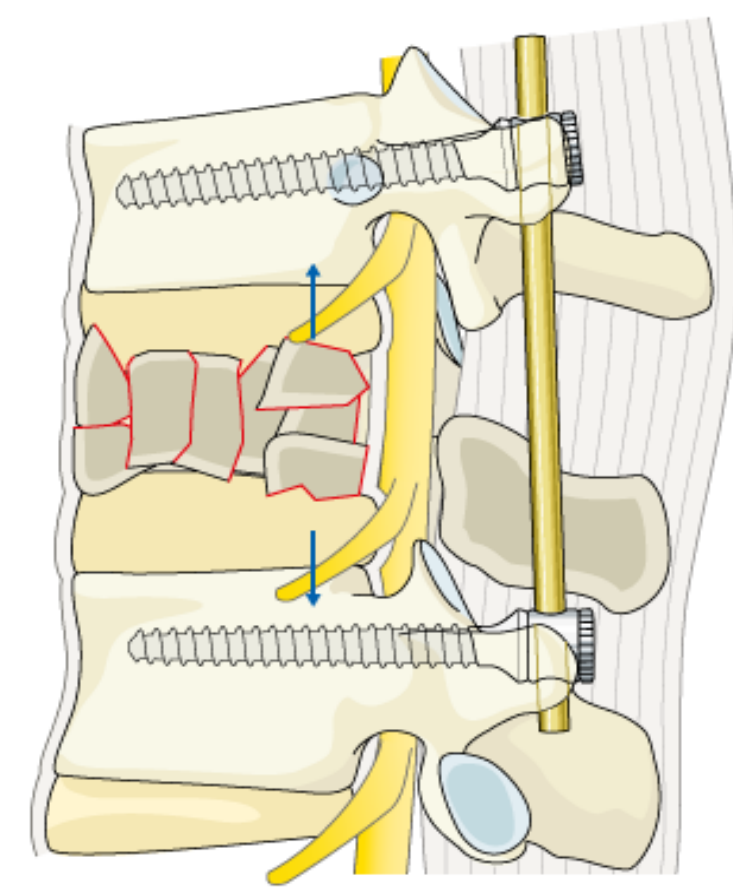

Fig 4: Ligamentotaxis by pedicle screw Source: https://www2.aofoundation.org

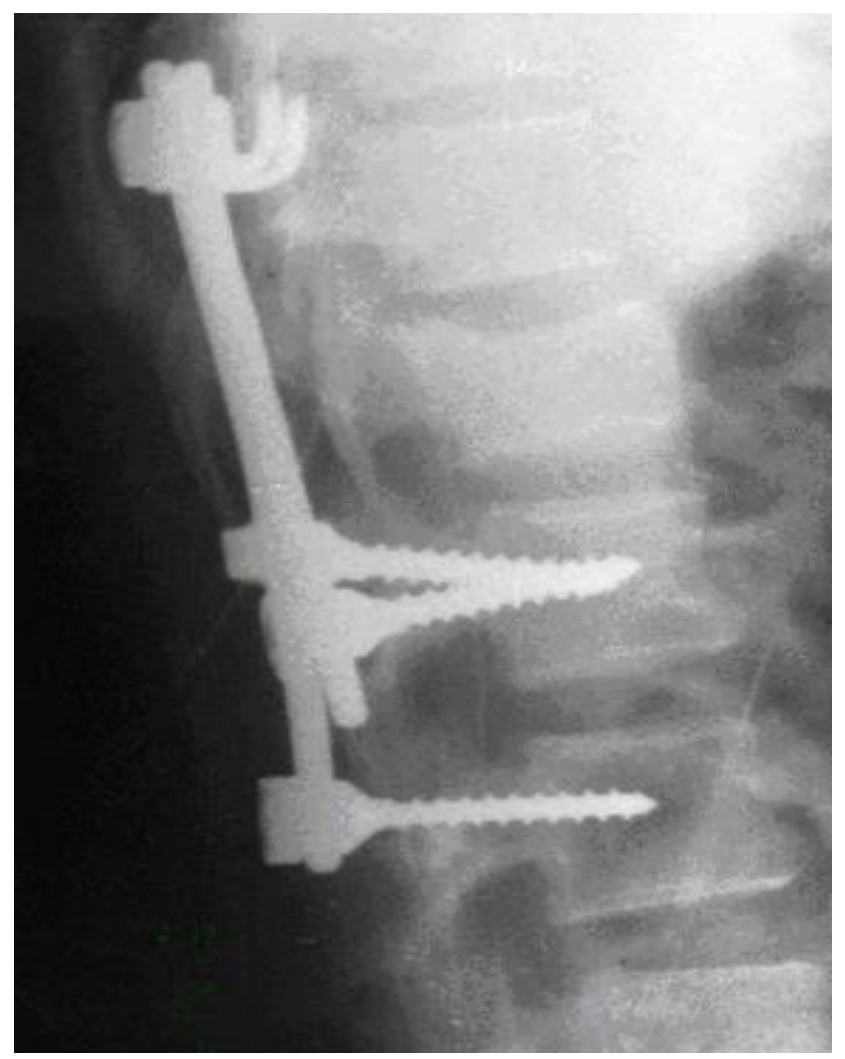

Fig 6: After Ligamentotaxis

If ligament taxis was not successful either direct posterior decompression or transpedicular route decompression with or without bone grafting was done.

Postoperatively patients were given analgesics, i.v antibiotic, bowel bladder back care and other nursing care. Patients were evaluated for improvement in neurological status whose charting was done for success of the treatment. Patients were mobilized with support after suture removal depending on stability and neurological status. 
Frequencies and proportions of characteristics under study were enlisted. As sample size was small, N1 Chi square test for small samples was used and online calculator was used. ${ }^{16}$

\section{RESULTS}

We enrolled total 19 patients with dorso-lumbar fractures during the study period.

$52.63 \%$ (10/19) patients had severe cord injuries. PLL rupture was significantly more to be ruptured in severe cord injury $(70 \%, 7 / 10$ cases). (Table 1)

PLL rupture was detected by MRI in $47.37 \%$ (9/19) patients and it was intact in remaining $52.63 \%$ (10/19) patients.

$52.63 \%(10 / 19)$ had wedge compression fracture. In all of them PLL was intact and $80 \%(8 / 10)$ of them received conservative treatment and $20 \%(2 / 10)$ got ligamentotaxis done. PLL was ruptured in all unstable burst fractures (6/6), flexion distraction injuries (1/1) and severe translational injuries (2/2). (Table 2) All of them received operative treatment in the form of Indirect reduction by ligamentotaxis. If ligamentotaxis was not successful either direct posterior decompression or transpedicular route decompression with or without bone grafting was done.

Indirect reduction by ligamentotaxis was done in 4 cases with intact PLL and success rate was 100\% (4/4). And, indirect reduction by ligamentotaxis was done in 7 cases with ruptured PLL and in all cases, 100\% (7/7) it was unsuccessful. Thus, ligamentotaxis worked very well if PLL was intact. (Table 3)

In patients with unsuccessful ligamentotaxis, direct decompression was required which was achieved in all of them. Out of them in four patients power did not improve, improvement was seen in $42.86 \%$ (3/7) cases.

Table 1: Posterior longitudinal ligament status and severe cord injuries

\begin{tabular}{lccc}
\hline PLL status & \multicolumn{2}{c}{ Severe Cord Injuries } & Total (\%) \\
\hline & Yes (\%) & No (\%) & \\
Intact & $3(30)$ & $7(70)$ & $10(100)$ \\
Ruptured & $7(77.78)$ & $2(22.22)$ & $9(100)$ \\
Total & $10(52.63)$ & $9(47.37)$ & $19(100)$ \\
\hline
\end{tabular}

By N1 Chi square test for two proportions, $p=0.042$

Table 2: Fracture pattern, PLL status and mode of treatment done

\begin{tabular}{lcccc}
\hline Fracture pattern & Total no & PLL status & \multicolumn{2}{c}{ Mode of treatment } \\
\hline \multirow{2}{*}{ Wedge compression } & (n) & Intact & Conserved & Operated \\
& 10 & Ruptured & 8 & 2 \\
Unstable brusts fracture & & Intact & 0 & 0 \\
& 6 & Ruptured & 0 & 0 \\
Flexion distractions & & Intact & 0 & 6 \\
& 1 & Ruptured & 0 & 0 \\
Translational slice , articular process & 2 & Intact & 0 & 1 \\
fracture, sublaxation dislocation & & & 0 & 0 \\
& & Ruptured & 8 & 2 \\
Total & 19 & & 0 \\
\hline
\end{tabular}

Table 3: Indirect reduction by ligamentotaxis

\begin{tabular}{lccc}
\hline PLL Status & \multicolumn{2}{c}{ Ligamentotaxis } & Total Attempted \\
\cline { 1 - 2 } Intact & Successful & Unsuccessful & \\
Ruptured & 4 & 0 & 4 \\
& 0 & 7 & 7 \\
& 4 & 7 & 11 \\
\hline
\end{tabular}

By N1 Chi square test for two proportions, $p=0.0016$

\section{DISCUSSION}

Prevention and limitation of neurological injury and restoration of spinal stability is a primary goal of management of spinal cord injuries. Correction of deformities, minimizing the loss of motion, and facilitating rapid rehabilitation are the secondary goals.

Ligamentotaxis can reduce only those retropulsed fragments that are still attached to a ligamentous structure. Where the PLL is intact, fragments near the midline are pulled back into place by the superficial fibres; fragments lying more laterally are reduced by their attachment to the deep layer. Continuity of the ALL ensures that overdistraction does not occur. The attachment of the annulus fibrosus to the endplates also probably contributes to the reduction by transferring distractive forces. ${ }^{17}$ Hence, if PLL is ruptured, pulling back will not be effective. The treatment of Denis' compression and burst fractures of the thoracolumbar and midlumbar spines still remains controversial. Good results were reported both in the nonoperative and operative treatment groups. Dennis middle column is formed of posterior part of vertebral body and PLL. Damage to two or three of dennis columns indicates instability in acute cases. Each column would heal if it has primarily bony injury but in the case of column with primarily ligamentous injury healing is inferior. ${ }^{18}$

Once surgery is decided to be done, the goals must be clearly defined. It aids the selection of the appropriate procedure to achieve optimal results. The major goals of the surgical treatment of the lower dorsal and lumbar spines are the restoration of normal spinal anatomy and neurological recovery. ${ }^{19}, 20$

Delay between injury and surgery, changes the efficiency of various surgical methods change. ${ }^{21}$ In this study, all the patients were arrived to the hospital within 48 hours of traumatic spinal injury. For old fractures which are over six weeks old, the mechanics of deformity correction are different because 
secondary changes have already occurred. The efficacy of indirect decompression was greater when surgery was performed as early as possible, particularly within three days after the trauma as reported by Myung-Sang Moon. ${ }^{22}$

The reduction of the retropulsed fracture fragments achieved through ligamentotaxis using pedicle screw enables indirect decompression of the spinal canal (Fig 3 and 4). Distraction of the rods should be performed gently and simultaneously on both sides. Sudden and rapid attempts at distraction places poses significant biomechanical stress on the screws. Asymmetrical distraction can result in unilateral wedging of the vertebral body. ${ }^{12,15}$

In reverse cortical sign as viewed by MRI, retropulsed fragment that has rotated more than 180 degrees so that the cortical surface is opposed to the cancellous surface of the main vertebral body. It is the absolute contraindication for posterior ligamentotaxis. ${ }^{14}$

Evaluation of main ligaments like anterior longitudinal ligament, posterior longitudinal ligament (PLL), ligamentum flavum as well as parenchymal lesions is possible only with MRI. These ligaments are important in spinal stability and planning surgical treatment in dorsolumbar fractures (Fig 1). ${ }^{5}$ Advantage of MRI is, intact ligaments are often difficult to see but disrupted ligaments more easily identified. ALL and PLL are seen most directly between the margin of high signal discs and subarachnoid space posteriorly or prevertebral fat anteriorly. PLL is best seen on T2 or photon density weighted images against high signal CSF. 5,19

We conclude that when posterior longitudinal ligamentotaxis is the operative treatment of choice in dorso-lumbar spine injuries, surgeon should be careful about intact PLL. As, Intact or ruptured PLL is best viewed by MRI, for spine injuries one should not rely only on skiagrams and CT.

\section{REFERENCES}

1. N Basheer MS, Deepak Gupta, GD Sathyarthi, Deepak Aggarwal , S Sinha, BS Sharma, et al. Unstable dorsolumbar fractures: A prospective series of 94 cases. Indian Journal of Neurotrauma (IJNT) 2010, Vol. 7, No. 1, pp. 55-60.

2. Gertzbein SD (1992) Fractures of the thoracic and lumbar spine. Williams \& Wilkins, Baltimore.

3. Reinhold M, Audigé L, Schnake K J, Bellabarba C, Dai L Y, Oner F C. AO spine injury classification system: a revision proposal for the thoracic and lumbar spine. Eur Spine J. 2013;22(10):21842201.[PMC free article] [PubMed])

4. Boos N, Aebi M: Spinal Disorders: Fundamentals of Diagnosis and Treatment New York,Springer, 2008. 1166 CrossRef Spinal Disorders. Fundamentals of Diagnosis and Treatment Thoracolumbar Spinal Injuries Michael Heinzelmann, Guido A. Wanner, 883)Editors: Boos, Norbert, Aebi, Max (Eds.)

5. Parizel PM, van der Zijden T, Gaudino S, et al.. Trauma of the spine and spinal cord: imaging strategies. Eur Spine J2010;19(Suppl 1):S8-S17.

6. Denis F, Armstrong GW, Searls K, Matta L (1984) Acute thoracolumbar burst fractures in the absence of neurologic deficit. $A$ comparison between operative and nonoperative treatment. Clin Orthop Relat Res 142-9.

7. Gertzbein SD (1992) Scoliosis Research Society. Multicenter spine fracture study. Spine 17:528-40

8. Kossmann T, Jacobi D, Trentz $O$ (2001) The use of a retractor system (SynFrame) for open, minimal invasive reconstruction of the anterior column of the thoracic and lumbar spine. Eur Spine J 10:396402

9. Arlet V, Orndorff DG, Jagannathan J, Dumont A. Reverse and pseudoreverse cortical sign in thoracolumbar burst fracture: radiologic description and distinction-a propos of three cases. Eur Spine $\mathrm{J}$ 2009;18:282-287.

10. Aebi M, Etter $C$, et al. The internal skeletal fixation system. A new treatment of thoracolumbar fractures and other spinal disorders. Clin Orthop Relat Res. 1988;227:30-43. [PubMed]

11. Mikles MR, Stchur RP, et al. Posterior instrumentation for thoracolumbar fractures. J Am Acad Orthop Surg. 2004;12(6):424435. [PubMed]

12. Roy-Camille R. Posterior screw plate fixation in thoracolumbar injuries. Instr Course Lect. 1992;41:157-163. [PubMed]

13. Zdeblick TA, Phillips FM. Interbody cage devices. Spine. 2003;28(Suppl 15):S2-S7. doi: 10.1097/00007632-200308011-00002. [PubMed] [Cross Ref]

14. Marre B (2007) Thoracic and lumbar spine trauma. In: Aebi M, Arlet V, Webb JK (eds) AOSpine manual. Thieme 2007, New York, pp 165-192

15. Terk MR, Hume-Neal M, Fraipont M, Ahmadi J, Colletti PM. Injury of the posterior ligament complex in patients with acute spinal trauma: evaluation by MR imaging. AJR Am J Roentgenol. 1997 Jun;168(6):1481-6.

16. Online $N$ chi square calculator. Available from [http://www.measuringu.com/ab-calc.php].

17. Fredrickson BE, Edwards WT, Rauschning W, Bayley JC, Yuan HA. Vertebral burst fractures: an experimental, morphologic, and radiographic study. Spine 1992; 17:1012-21.

18. Denis $F(1983)$ The three column spine and its significance in the classification of acute thoracolumbar spinal injuries. Spine 8:817-831. 19. Lennard A Nadalo. Spinal Stenosis Imaging. Medscape. Updated on 9.1.16. \{Accessed on 3.6.16\}. [Available from http://emedicine.medscape.com/article/344171-overview,

20. Moon MS, Choi WT, Moon YW, Kim YS, Moon JL. Stabilisation of fractured thoracic and lumbar spine with Cotrel-Dubousset instrument.J Orthop Surg (Hong Kong). 2003 Jun; 11(1):5966.[PubMed] [Ref list]

21. Mikles MR, Stchur RP, Graziano GP. Posterior instrumentation for thoracolumbar fractures.J Am Acad Orthop Surg. 2004 Nov-Dec; 12(6):424-35.

22. Moon MS, Choi WT, Sun DH, Chae JW, Ryu JS, et al. Instrumented ligamentotaxis and stabilization of compression and burst fractures of dorsolumbar and mid-lumbar spines Indian J Orthop. 2007 Oct-Dec; 41(4): 346-353

Source of Support: Nil.

Conflict of Interest: None Declared.

Copyright: (c) the author(s) and publisher. IJMRP is an official publication of Ibn Sina Academy of Medieval Medicine \& Sciences, registered in 2001 under Indian Trusts Act, 1882.

This is an open access article distributed under the terms of the Creative Commons Attribution Non-commercial License, which permits unrestricted non-commercial use, distribution, and reproduction in any medium, provided the original work is properly cited.

Cite this article as: Borkar Santosh S, Konde Shivraj S, Kulkarni Priya Y, Borkar Sumita S. Efficacy of Ligamentotaxis of the Intact and Ruptured Posterior Longitudinal Ligament in Dorso-Lumbar Traumatic Spine Injuries. Int J Med Res Prof. 2016; 2(4):98-102. 